\title{
Effects of ambient lighting and the albino gene on the developing visual evoked potential of the mouse
}

\author{
KENNETH R. HENRY, ROBERT W. RHOADES, and MARK M. HAYTHORN \\ University of California, Davis, California 95616
}

\begin{abstract}
C57BL/6J inbred mice, congenic for the c (albino) gene, were bred and reared under cyclic conditions of either bright or dim ambient lighting. At 53 days postpartum, the cortical visual evoked potential (VEP) was measured in the light-adapted subject. The $\mathrm{P}_{2}$ latency was shortest in the $+/+$ (pigmented) genotype, longest in the c/c (albino) mouse, and intermediate in the $+/ \mathrm{c}$ (pigmented heterozygote). In agreement with another experiment involving the albino rat, mice reared in dim light had smaller $\mathrm{P}_{1} \mathrm{~N}_{2}$ amplitudes than those reared in bright light. However, the effects of environmental lighting on the VEP amplitudes in the present study were primarily due to the presence of the albino gene. Melanin, per se, is considered not to be the primary relevant factor, because of intermediate latencies of the pigmented heterozygote. However, enzymes altered by the c gene are considered as a possible factor. The data were discussed in terms of DeFries' (1969) concept of pleiotrophism of the albino gene for visual and other behaviors.
\end{abstract}

Both genetic factors and the visual environment have profound effects upon the visual system. Many studies have examined only one of these variables, thereby missing important genotype-environmental interactions which might otherwise have been observed. The present experiments examine, not only the effects of single gene substitutions on the cortical visual evoked potential (VEP), but also the manner in which different visual environments alter the expression of this visual phenotype.

The albino (c/c) mammal displays many visual properties which differ from those seen in their ocularly pigmented counterparts. Albino rodents (Lund, 1965), carnivores (Guillery, Casagrande, \& Oberdorfer, 1974), and humans (Guillery, Okoro, \& Witkop, 1975) have anomalous visual pathways. The albino mouse is also deficient in several behaviors, when compared with its pigmented littermates (DeFries, 1969; Thiessen, Owen, \& Whitset, 1970), and some of these differences are single albino gene effects; i.e., the $+/ c$ avoidance learning performance is intermediate to those of the $\mathrm{c} / \mathrm{c}$ and $+/+$ genotypes (Rhoades \& Henry, 1976). This paper reports that these single-gene substitutions also influence the visual evoked potential.

Although many types of visual environment can affect subsequent visual processing, those that are experienced early in life often produce the most dramatic effects. Thus, restriction of patterned visual

This research was supported by National Institute of Neurological Diseases and Stroke Grant NS-11565 to the senior author. Requests for reprints should be sent to Kenneth R. Henry, Department of Psychology, University of California, Davis, California 95616. input to a single eye for the first 28-42 days after birth will functionally limit the properties of cortical neurons which have not had exposure to visual forms (see Blakemore, 1974, for review). When albino rats are reared in very dim illumination, the $\mathrm{N}_{1} \mathrm{P}_{2}$ components of their VEPs were of lower amplitudes than those of littermates maintained under standard laboratory lighting (Rhodes \& Fleming, 1970). Creel, Dustman, and Beck (1970) also found that albino rats have longer VEP latencies than ocularly pigmented hooded rats, and considered several ways in which the lack of melanin pigmentation could account for this effect.

The present study generalizes these findings to the mouse. It suggests the importance of the albino gene to reduced VEP amplitudes in subjects reared in dim light, and the lack of relationship of ocular melanin, per se, to the longer latencies of the albino.

\section{METHOD}

The inbred C57BL/6 mouse strain, congenic for the $\mathrm{c}$ gene, was used in this study. They originated from $\mathrm{C} 57 \mathrm{BL} / 6 \mathrm{~J}$ and C57BL $/ 6^{\mathrm{cIJ}}$ mice from the Jackson Laboratory, and have been bred for over six generations in our colony. They provided 54 subjects which are identifiable as $+/+$ (black phenotype), $+/ \mathrm{c}$ (black phenotype), or c/c (albino phenotype) genotypes (Henry \& Haythorn, 1975), although they are virtually identical for all other genes. Nine mice of each genotype were used for each condition.

All subjects were reared in translucent plastic cages with both parents. Ad-lib access to tap water and Purina Laboratory Chow was allowed. At 21-25 days postpartum, they were weaned into cages containing 3-5 littermates.

The subjects spent their entire lives, from conception until testing, in either a bright ( $16 \mathrm{fc}$, at the level of the mouse in the cage) or a dim $(0.25 \mathrm{fc})$ environment. Both groups were maintained on a 12-h day-night cycle, and each group was tested between the 7 th and 12 th hours of their 12-h day. 
At 7 weeks postpartum, all the subjects were anesthetized with sodium pentobarbital $(60 \mathrm{mg} / \mathrm{kg}$, IP). Three microliters of atropine sulfate $(2 \mathrm{mg} / \mathrm{cc}$, IP) were also administered to counteract the respiratory effects of the anesthesia. Stainless steel screw electrodes were tapped into the skull, with their $0.8-\mathrm{mm}^{2}$ surface coming into direct contact with the dura. Each subject was implanted with two active occipital electrodes, located $1 \mathrm{~mm}$ anterior to lambda and $2 \mathrm{~mm}$ lateral to the sagittal suture. The two reference electrodes were located $6 \mathrm{~mm}$ anterior to lambda and $2 \mathrm{~mm}$ lateral to the sagittal suture. All impedances were less than $5 \mathrm{~K} \Omega$, at $10 \mathrm{~Hz}$. All subjects recovered for 4 days in their home environments prior to testing. No subjects tested lost more than $0.5 \mathrm{~g}$ body weight between surgery and recording.

The VEPs were recorded from light-adapted mice under sodium pentobarbital anesthesia. Pupils were maximally dilated with atropine. The unrestrained mice were positioned on a pedestal with their heads resting on a bite bar. A plastic hemisphere (23-cm diameter), painted white and mirrored with silver over $75 \%$ of its outer surface, was then placed over the subject. The flash unit of a Grass PS-22 photostimulator was positioned behind the clear portion of the dome at the rear of the mouse. Light from this unit was diffused by the white paint and reflected into the eyes of the subject. The subjects were stimulated at a rate of $1 \mathrm{flash} / \mathrm{sec}$, at intensities of 1,4 , and 16 on the photostimulator. All testing was performed in an acoustically and electrically insulated chamber.

The VEPs were amplified by a Grass P-15 preamplifier (bandpass of $0.3-300 \mathrm{~Hz}$ ) before being processed by a Tracor Northern 575-A signal averager. System calibration was conducted by passing a $10-\mathrm{Hz}, 10-\mu \mathrm{V}$ signal from a Grass SW1 calibrator (used as a voltage divider) through the entire system. Signals were collected for $154 \mathrm{msec}$ after the flash onset, digitized with 9-bit resolution, and stored in one of 512 addresses using a time base of $300 \mu \mathrm{sec}$ per address. Each VEP was averaged from 64 flashes and plotted on graph paper, from which the amplitude of the $\mathrm{N}_{1} \mathrm{P}_{2}$ and the latency of the $\mathrm{P}_{2}$ component were measured. The $\mathrm{N}_{1} \mathrm{P}_{2}$ amplitude was chosen because of its relationship to the retino-geniculate system and the fact that it has been found to increase with flash intensity (Creel, Dustman, \& Beck, 1974). It was also measured because Rhodes and Fleming (1970) observed it to decrease in albino rats reared in dimly lit environments. The $P_{2}$ latency was chosen because Creel et al. (1970) associated an increased $\mathrm{P}_{2}$ latency with decreased ocular melanin in the albino rat, and because of its independence of stimulus intensity (Creel et al., 1974).

No significant differences in either measure were found between the right and left hemispheres, indicating uniformity of electrode placement. This enabled us to use the average of the two hemispheres as a more stable measure of the VEP. Initial analysis of the data utilized a repeated measure analysis of variance. Since our subjects varied in an interval fashion in the number of albino genes they possessed, the VEPs of the $+/+,+/ c$, and $c / c$ genotypes were subsequently analyzed with the powerful orthogonal polynomial analysis (Henry \& Bowman, 1970).

\section{RESULTS}

Typical VEPs for the C57BL/6 mouse are shown in Figure 1. Genotype had a very strong influence on the VEP latency (Figure 2). The $\mathrm{P}_{2}$ component of the $\mathrm{c} / \mathrm{c}$ (albino) VEP occurred after that of the $+/+$ (pigmented), and the $+/ c$ (pigmented) latency was intermediate. Subsequent trend analysis indicated that this effect was associated with single $c$ gene additions (linear $\mathrm{F}=16.55$, df $=1 / 48, \mathrm{p}<.0001$, accounting for $24.7 \%$ of the variance). This latency effect was not related to ocular pigmentation (quadratic $\mathrm{F}<1.0$ ). Latencies did not change as a function of flash intensity $(F<1.0)$, nor did they vary between mice reared under the two conditions $(F=1.6)$. None of the interactions were significant in this analysis.

The $\mathrm{N}_{1} \mathrm{P}_{2}$ amplitudes increased as a function of flash intensity $(F=185.3, \mathrm{df}=2 / 96, \mathrm{p}<.0001)$. The visual environment in which the subjects were born and housed also had a major effect on the $\mathrm{N}_{1} \mathrm{P}_{2}$ amplitudes (Figure 3). Mice in the brighter environment had larger VEP amplitudes $(F=9.32$, df $=$ $1 / 48, p<.005)$. Although genotype, per se, had no influence on $\mathrm{N}_{1} \mathrm{P}_{2}$ amplitudes $(\mathrm{F}<1)$, the significant Rearing by Genotype by Intensity $(F=2.33$, df $=2 / 96, p<.05$ ) and Genotype by Intensity $(F=3.55, \mathrm{df}=2 / 96, \mathrm{p}<.025)$ interactions are revealed in Figure 4. When these data were collapsed across intensities (Figure 5), the VEP amplitude was only significantly reduced by dark rearing in the albino mouse $(\mathrm{t}=2.63, \mathrm{df}=17, \mathrm{p}<.02)$.
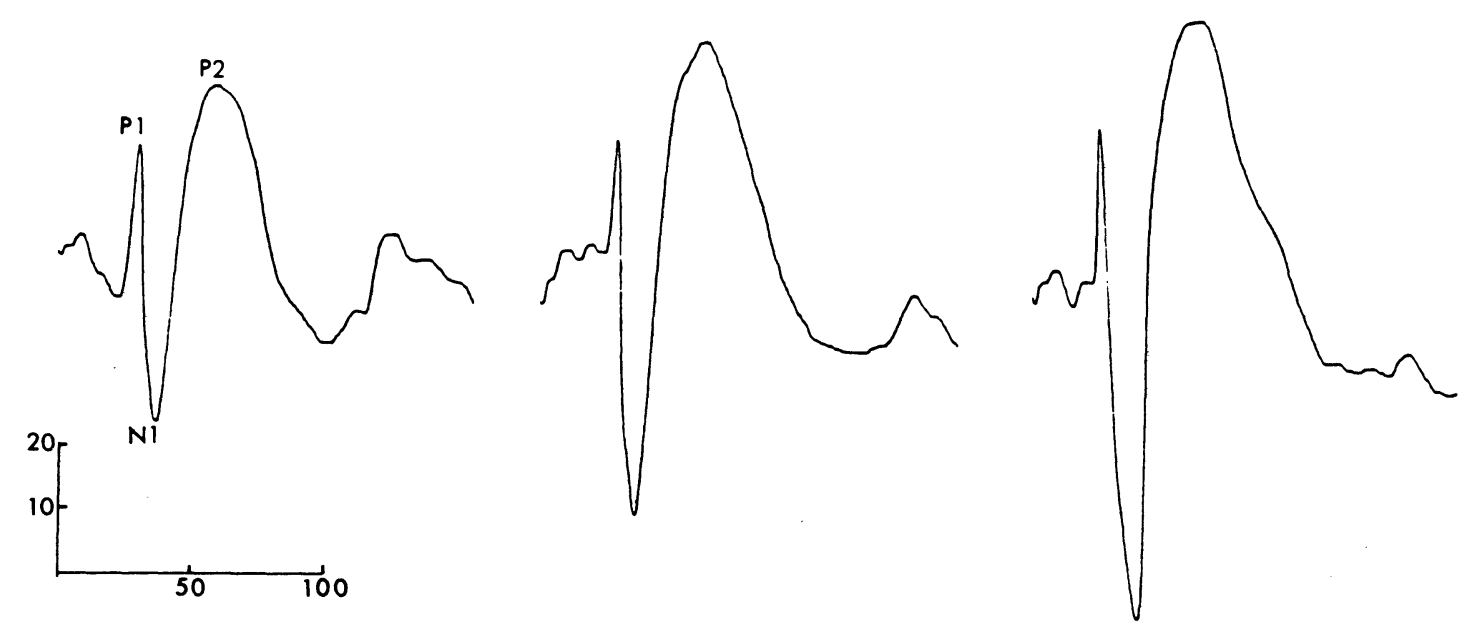

Figure 1. Representative visual evoked potentials (VEPs) from the C57BL/6 mouse at three flash intensities. Horizontal calibration is 100 msec; vertial is $20 \mu \mathrm{V}$. 


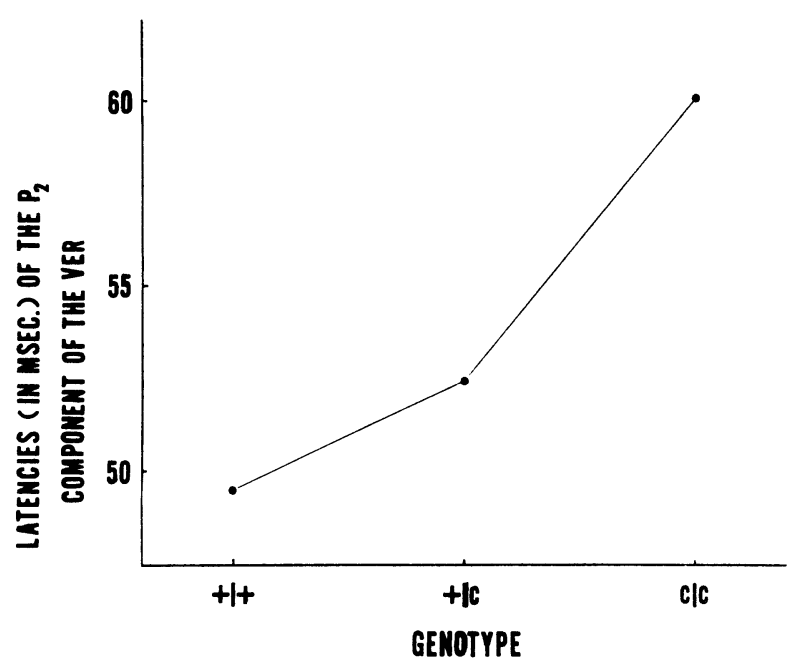

Figure 2. VEP latencies, collapsed across flash intensities, as a function of single albino gene substitutions in the $\mathrm{C57BL} / 6 \mathrm{~J}$ mouse.

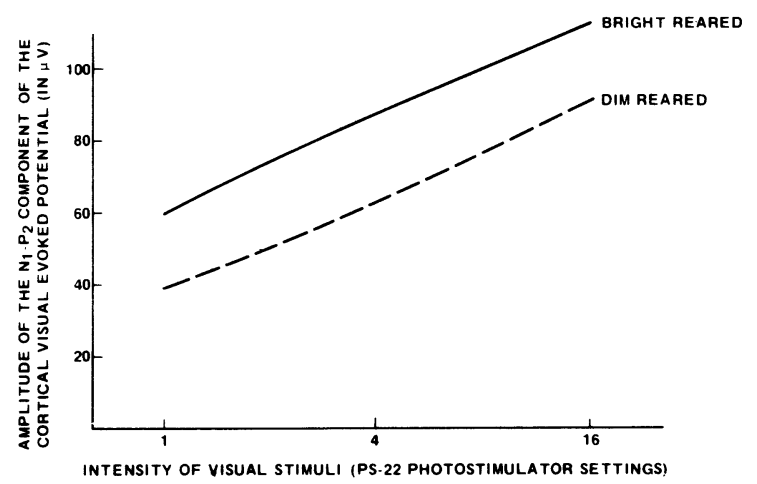

Figure 3. VEP amplitudes at three flash intensities, collapsed across genotype, as a function of rearing in bright and dim visual environments.

\section{DISCUSSION}

The data suggest that the cortical VEP is influenced by the albino (c) gene, and that some of these effects interact with the visual environment in which the mouse is reared. Although they replicate and generalize to another species and the findings of other experiments, they also suggest alternative explanations for the data.

Creel et al. (1970) found that the latency of the $\mathrm{P}_{2}$ component was longer in the awake albino than in the awake hooded rat. We found an identical result in a comparison of the anesthetized $\mathrm{c} / \mathrm{c}$ with the anesthetized $+/+\mathrm{C57BL} / 6 \mathrm{~J}$ mouse. They suggested that lack of ocular pigment in the albino accounted for their differences. The inclusion of data from the heterozygote $(+/ \mathrm{c})$ genotype precludes such an explanation in the present study, since the heterozygote has a latency halfway between that of the $\mathrm{c} / \mathrm{c}$ and $+/+$ mouse, as indicated by the strong linear trend. This increase in latency is linearly related to single $c$ gene substitutions. The genetic effect is robust, as indicated by the large percentage of variance it accounts for in our data and by the similar increase which Creel et al. (1970) observed in the comparison of pigmented and albino rats. It also displays a marked resistance to environmental influences, which is demonstrated by its presence in both the awake (Creel et al., 1970) and anesthetized (present study) rodent by the lack of influence of ambient environmental lighting and by its independence of flash intensity.

In contrast, the $\mathrm{N}_{1} \mathrm{P}_{2}$ amplitude was greatly influenced by environmental factors. Here the only significant genetic influence occurs in the form of a Genotype by Environmental interaction. The basic finding of Rhodes and Fleming (1970) was replicated, with subjects reared in dim light having $\mathrm{N}_{1} \mathrm{P}_{\mathbf{2}}$ VEP amplitudes smaller than those of rodents reared under standard laboratory illumination. Additional evidence for environmental control over this component was seen in its linear relationship to stimulus intensity. Rhodes and Fleming (1970) made this observation using albino rats, while Figure 4 indicates

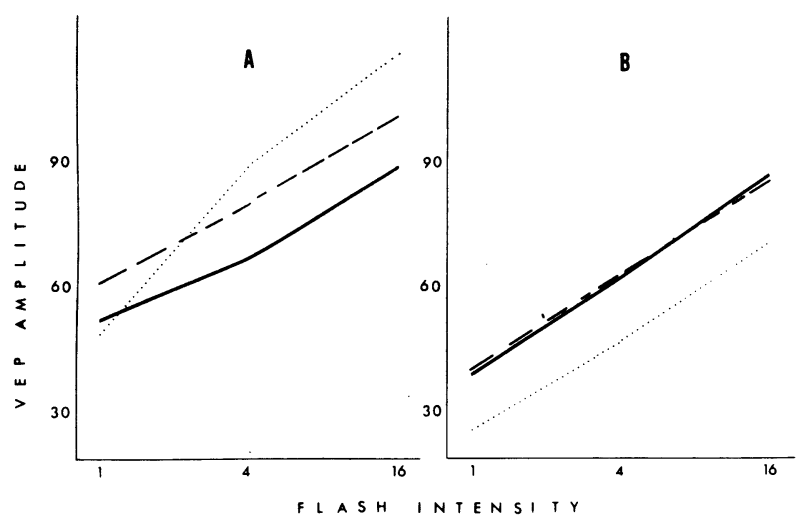

Figure 4. VEP amplitudes in light-reared (A) and dark-reared (B) mice of the $+/+$ (solid line), $+/ c$ (broken line), and c/c (dotted line) genotypes.

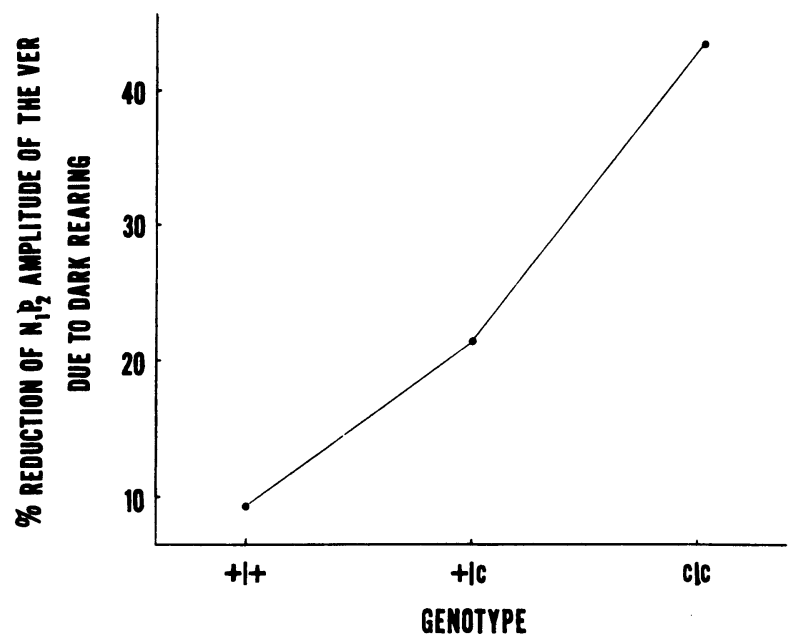

Figure 5. Effect of genotype collapsed across flash intensities. 
that the effects we observed were primarily due to the presence of albino genes in our subjects. The amplitude decrement is pronounced in the dimreared $\mathrm{c} / \mathrm{c}$ mouse, and quite small in the $+/+$ animal. Although the heterozygote did not show a significant decrement, its intermediate position leaves us uncertain as to whether this is best described as a $c$ gene or a melanin effect. The data of Figure 4A suggest that these relationships might differ as a function of flash intensity.

This does not imply that nonalbinic mammals will not show any effects of early visual environment on VEP amplitudes, since Rose and Gruenau (1973) reported that pigmented cats reared in constant light have longer VEP amplitudes than cats reared under 12-h light-dark cycles. Constant illumination, however, has its own unique effects on the visual system (Anderson, Coyle, \& O'Steen, 1972; Kaitz, 1976), so our results might not be expected to be comparable with theirs.

Albino rodents also suffer greater effects of retinal degeneration than do ocularly pigmented subjects (LaVail \& Battelle, 1975; Reiter, 1973), but this effect requires noncycling light of a greater intensity than that employed in the present study, so it is doubtful that photically induced retinal degeneration was a factor here.

Another possible explanation for the reduction of VEP amplitude due to dim rearing being restricted to albinos could be that these subject's eyes were more quickly traumatized by the light than were the eyes of pigmented mice. However, several facts argue against this interpretation. First, the amplitude decrement was found at all three intensities, while fatigue would be expected to be influential only at brighter illuminations. Second, the topical applications of atropine sulfate produced maximum pupillary dilation for all subjects. And third, Kaitz (1976) has reported that dark rearing protects rats from retinal damage due to subsequent overexposure to intense light.

The present binocular study did not directly address the question of the origin of the early components of the VEP. Creel, Dustman, and Beck (1970) found qualitative differences between the early components of the monocular VEP of hooded and albino rats which were compatible with anatomical differences of their ipsilateral visual pathways. We have performed a similar (unpublished) subsequent experiment with the mice of the present study, but found no qualitative differences among the three genotypes. However, genotypic differences between the ratio of contralteralto-ipsilateral VEP measures were compatible with the reduced ipsilateral pathway in the albino mammal. Unfortunately, these ratios varied from 3:1 to 5:1, while the ipsilateral pathway of the rodent carries less than $5 \%$ of the number of fibers found in its contralateral pathway. Therefore, the high degree of volume conduction in the small brain of the mouse did not allow us to use the VEP to determine the relative contribution of the two eyes to the data described above.

Although the visual abnormalities of albinic mammals have been most closely associated with reduced levels of ocular melanin (Creel \& Giolli, 1976; Sanderson, Guillery, \& Shackelford, 1974), the albino rodent is also deficient in many nonvisual behaviors (see Thiessen et al., 1970, for a review). This has led to DeFries' (1969) describing the albino as displaying a behavioral pleiotropism. We believe that this concept should be expanded, with albino genes being considered as producing neurobehavioral pleiotropism. For example, the albino mouse has less of a preference for drinking an alcohol solution than its pigmented littermate (Henry \& Schlesinger, 1967), and the heterozygote is intermediate (King \& Rush, Note 1). Both auditory behaviors and inferior collicular evoked potentials develop in a different fashion as a result of single albino gene substitutions (Haythorn \& Henry, 1975; Henry \& Haythorn, 1975). These differences may be related to the multiple biochemical effects of X-ray-induced mutations at the albino locus in the mouse (Thorndike, Trigg, Stockert, Gluecksohn-Waelsch, \& Cori, 1973). These neurobehavioral abnormalities may also be related to the anomalous forebrain projections which Wahlsten (1974) has observed in some mice. His data suggest that these anomalies are most likely to occur in subjects possessing at least one $c$ gene. These aberrant projections might occur as a result of an abnormal or delayed developmental sequence due to the c gene. This could explain the delayed auditory development associated with single albino gene substitutions (Haythorn \& Henry, 1975; Henry \& Haythorn, 1975). It would also be compatible with the data of the present study.

\section{REFERENCE NOTE}

1. King, R. A., \& Rush, W. A. Alcohol sensitivity in the albino mouse. Paper presented at the Ninth International Pigment Cell Conference, January 1975.

\section{REFERENCES}

Anderson, K. V., Coyle, F. P., \& O'Steen, W. K. Retinal degeneration produced by low-intensity colored light. Experimental Neurology, 1972, 35, 233-238.

Blakemore, C. Developmental factors in the formation of feature extracting neurons. In F. O. Schmitt \& F. G. Worden (Eds.), The neurosciences: Third study program. Cambridge. Mass: M.I.T. Press, 1974.

Creel. D. J., Dustman, R. E., \& Beck, E. C. Differences in visually evoked responses in albino versus hooded rats. Experimental Neurology, 1970, 29, 298-309.

Creel, D., Dustman, R. E., \& Beck, E. C. Intensity of flash illumination and the visually evoked potential of rats. guinea pigs and cats. Vision Research, 1974, 14, 725-729.

Creel, D., \& Giolli. R. A. Retinogeniculate projections in 
albino and ocularly hypopigmented rats. Journal of Comparative Neurology, 1976, 166, 445-456.

DeFries, J. C. Pleiotropic effects of albinism on open field behaviour in mice. Nature, 1969, 221, 65-66.

Guillery, R. W., Casagrande, V. A., \& Oberdorfer, M. D. Congenitally abnormal vision in siamese cats. Nature, 1974, 252, 195-199.

Guillery, R. W., Okoro, A. N., \& Witkop, C. J., JR. Abnormal visual pathways in the brain of a human albino. Brain Research, 1975, 96, 373-377.

HAythorn, M. M., \& HenRy, K. R. Albinism and auditory function in the laboratory mouse. II. Effects of acoustic priming and cross-fostering. Behavior Genetics, 1975, 5, 321-329.

HENRY, K. R., \& Bowman, R. E. Behavior-genetic analysis of the ontogeny of acoustically primed audiogenic seizures in mice. Journal of Comparative and Physiological Psychology, 1970, 70. 235-241.

HENRY, K. R., \& HAYThoRN, M. M. Albinism and auditory function in the laboratory mouse. I. Effects of single-gene substitutions on auditory physiology, audiogenic seizures, and developmental processes. Behavior Genetics, 1975, 5, 137-149.

HeNRY, K. R., \& Schlesinger, K. Effects of the albino and dilute loci on mouse behavior. Journal of Comparative and Physiological Psychology, 1967, 63, 320-323.

KAITZ, M. Protection of the dystrophic retina from susceptibility to light stress. Investigative Ophthalmology, 1976, 15, 153-156.

LAVAIL, M. M., \& BaTTELle, B.-A. Influence of eye pigmentation and light deprivation on inherited retinal dystrophy in the rat. Experimental Eye Research, 1975, 21, 167-192.

LUND, R. D. Uncrossed visual pathways of hooded and albino rats. Science, 1965, 149, 1506-1507.

ReIter, R. J. Comparative effects of continual lighting and pinealectomy on the eyes, the harderian glands and repro- duction in pigmented and albino rats. Comparative Biochemical Physiology, 1973, 44A, 503-509.

RhoAdes, R. W., \& Henry, K. R. Effects of the albinic allele on the performance of mice in a compound avoidance-discrimination task. Western Psychological Association Program, 1976. 77. (Abstract)

Rhodes, L. E., \& Fleming, D. E. Sensory restriction in the albino rat: Photically evoked after-discharge correlates. Electroencephalography and Clinical Neurophysiology, 1970, 29. 488-495.

Rose, G. H., \& Gruenau, S. P. Alterations in visual evoked responses and behavior in kittens reared under constant illumination. Developmental Psychobiology, 1973, 6, 69-77.

Sanderson, K. J., Guillery, R. W., \& Shackelford, R. M. Congenitally abnormal visual pathways in mink (Mustela vison) with reduced retinal pigment. Journal of Comparative Neurology, 1974, 154, 225-248.

Thiessen, D. D., Owen, K., \& Whitset, M. Chromosome mapping of behavioral activities. In G. Lindzey \& D. D. Thiessen (Eds.), Contributions to behavior-genetic analysis: The mouse as a prototype. New York: Appleton-Century-Crofts, 1970. Pp. 161-204.

Thorndike, J. Trigg, M. J., Stockert, R., GluecksohnWAELSCH, S., \& CoRI, C. F. Multiple biochemical effects of a series of X-ray induced mutations at the albino locus in the mouse. Biochemical Genetics, 1973, 9. 25-39.

W AHLSTEN, D. Heritable aspects of anomalous myelinated fibre tracts in the forebrain of the laboratory mouse. Brain Research, 1974, 68, 1-18.

(Received for publication September 27, 1976; revision accepted December 10, 1976.) 